REVISTA DE DERECHO UNED, núm. 4, 2009

\title{
A PROPÓSITO DE ALGUNAS RELECCIONES DE FRANCISCO DE VITORIA
}

\author{
RAMÓn J. Fernández de Marcos Morales ${ }^{1}$
}

Resumen: En este estudio analizaremos algunas de las relecciones más conocidas de F. de Vitoria, como De indis, De iure belli, De potestate civili, o De potestate Ecclessiae, por entender que es ahí donde se encuentran las ideas fundamentales para conocer la antropología vitoriana.

Tal y como hacían los antiguos escolásticos, F. de Vitoria inicia el análisis de sus proposiciones con la exposición de la opinión contraria a la que él mantiene, y a continuación defiende su opinión.

F. de Vitoria cuestiona, desde su cátedra, la supremacía del Papa y del Emperador Carlos V, quien finalmente tendría en cuenta las opiniones del dominico nombrándole teólogo imperial.

La figura de F. de Vitoria fue olvidada durante siglos, no así su doctrina sobre los derechos humanos, la cual se infiltró en nuestra realidad histórica y social de forma permanente en las constituciones y democracias actuales.

Abstract: In this study we will analyze some of the relessons more known of F. de Vitoria, like Relectio De indis, Relectio De iure belli, Relectio De potestate civili, Relectio De potestate Ecclessiae, for understanding that it is there where they find the fundamental ideas to know the vitorian anthropology.

As they were doing the former scholastic ones, F. de Vitoria initiates the analysis of his propositions with the exhibition of the oppo-

\footnotetext{
${ }^{1}$ Profesor Doctor Asociado del Departamento de Derecho Romano de la Facultad de Derecho de la UNED.
} 
site opinion to the one that he supports, and later he defends his opinion. F. de Vitoria questions, from his chair, the supremacy of the Pope and of the Emperor Carlos V, who finally would bear in mind the opinions of the dominican nominating him an imperial theologian.

The figure of F. de Vitoria was forgotten for centuries, not this way his doctrine on the human rights, which infiltrated into our historical and social reality permanently in the current constitutions and democracies.

Sumario: 1. Introducción.-2. Relecciones de Francisco de Vitoria.-3. El olvido del maestro Vitoria.-4. A modo de conclusión.

«Señor secretario general, señoras y señores. Este es el recuerdo que hoy ofrezco a la Organización de las Naciones Unidas. Os traigo la efigie de Francisco de Vitoria, humilde fraile y gran filósofo, que definió para siempre los fundamentos del derecho internacional cuyas reglas, respetadas por todos los Estados miembros, son cimiento mismo de esta organización».

Juan Carlos I rey de España (Naciones Unidas 1976)

\section{INTRODUCCIÓN}

Incomprensiblemente, Francisco de Vitoria ha sido ignorado, durante más de dos siglos, por los juristas españoles y extranjeros. Por este motivo, siempre que nos acerquemos a su figura, no haremos otra cosa que devolverle una parte de la deuda que, aun al día de hoy, tenemos contraída con él.

Para comprender a un autor y a su obra, es necesario conocer algunos datos sobre su biografía, pero también adentrarnos en su pensamiento y en su doctrina. En el caso de Vitoria, cuando leemos una cualquiera de sus relecciones, sentimos la necesidad de terminar su lectura y volver a leerla más despacio, por este motivo centraremos el objeto del presente estudio en ciertos aspectos de algunas de sus relecciones ${ }^{2}$ más conocidas, y porque además, como sostiene

${ }^{2}$ Omitiremos muchas de ellas, las menos conocidas, como Relectio De Matrimonio, motivada por la cuestión del divorcio de Enrique VIII de su esposa española Catalina de Aragón, hija de los reyes católicos, tía de Carlos V, o Relectio De homicidio, por ejemplo. 
Diaz $^{3}$, es ahí donde se contienen las ideas fundamentales para comprender la antropología vitoriana.

Al igual que los antiguos escolásticos, F. de Vitoria inicia el análisis de sus proposiciones con la exposición de la opinión contraria a la que él mantiene, y a continuación defiende la suya. Trata cuantas cuestiones considera conveniente, y sobre ellas realiza las proposiciones correspondientes, sobre las cuales en ocasiones plantea dudas (hasta doce como es caso de Relectio De iure belli), donde finaliza con reglas conclusivas, añadiendo constantemente «y lo pruebo»o "pruébase con».

Como teólogo que es, prueba sus afirmaciones principalmente con textos de Santo Tomás, y también de San Agustín, San Isidoro y, por supuesto, de la Biblia, entre otros. En este punto, podríamos plantearnos una primera cuestión: ¿Qué tiene que decir un teólogo acerca de la jurisdicción de los derechos humanos o de gentes?.

Sobre este particular, F. de Vitoria, al comienzo De potestate civili, dice: «El deber, la misión del teólogo son tan extensos que no hay argumento alguno, no hay disputa, no hay tema ajeno a la profesión e institución teológica» y, un siglo más tarde, Francisco Suárez en su Tratado De Legibus ac Deo legislatore, añade: «A nadie debe sorprender que un teólogo se dedique a escribir leyes. El alto rango que la teología posee y que le viene de Aquel que constituye su muy elevado objeto, disipa cualquier motivo de sorpresa. Es más, si nos fijamos bien, nos daremos perfecta cuenta de que hablar de leyes entra dentro del ámbito de la teología, de tal forma que no podrá el teólogo agotar hasta el fondo la materia teológica, si no se detiene a estudiar las leyes».

Es importante destacar en primer lugar, que las relecciones fueron dictadas y escritas en latín, pero nosotros hemos manejado la traducción preparada y dirigida por Juan Cruz, catedrático de la Universidad de Navarra. En segundo lugar, que en alguna relección como en la Relectio De Potestate Ecclesiae, podría tratarse no de una sola relección sino de dos o más, porque Vitoria dice, por ejemplo, que va a hablar de la naturaleza y efectos de la excomunión, y luego relega a lo dicho. En tercer lugar, cuando habla de conclusión, indistintamente se refiere a proposición o argumento, como en la $R e-$ lectio De Potestate civili. En cuarto y último lugar, señalar que este trabajo no pretende ni mucho menos ser determinante, sino única-

${ }^{3}$ Cfr.DÍAZ, Bárbara, El internacionalismo de Vitoria en la era de la globalización, Cuadernos del Pensamiento Español n. ${ }^{\circ}$ 27, 2005, p. 26. 
mente dar unas pequeñas e insuficientes pinceladas (pido disculpas anticipadas por ello) acerca del pensamiento vitoriano. Por ello he sintetizado las propuestas, cuestiones y/o argumentos, para conseguir una mayor unidad material de la doctrina vitoriana, ya que lo contrario excedería con mucho las características de esta publicación.

Por otra parte, como hemos dicho, también son necesarios algunos datos biográficos, para situar al dominico en su entorno. Así pues, sabemos que Francisco de Vitoria, teólogo y jurista universitario, era contemporáneo del Cardenal Cisneros, de Cristóbal Colón, de los Reyes Católicos, o de Carlos V, bajo cuyo reinado transcurrió la mayor parte de su vida, cuando España dominaba Europa y el Mundo.

Nace en Burgos, o más probablemente en Vitoria, entre 1483 y 1492, cuando Cristóbal Colón descubría el Nuevo Mundo. En 1504 ingresa en la orden fundada por Santo Domingo de Guzmán, dedicada al estudio y a la predicación. En 1505, es destinado al convento de San Pablo de Burgos, donde permaneció hasta 1508, año en el que fue trasladado a París, al Colegio Saint-Jacques, que la orden dominica tenía en la Sorbona, y donde en 1513 comenzó su actividad docente.

En 1522, convertido ya en Doctor en Teología por la Sorbona, regresa a Valladolid, sede del Gobierno en la época. En 1526 oposita, con éxito, a la Cátedra de Teología en Salamanca, trasladándose a dicha ciudad para continuar su actividad docente.

Como jurista, estudió los límites del poder civil y eclesiástico. Se enfrentó a las ideas medievales: la supremacía universal del Papa o del Emperador, de forma que el poder civil está sujeto a la autoridad espiritual del papado, pero no a su poder temporal. Y como teólogo, y al ser la teología una ciencia que lo comprendía todo, estudió todos los asuntos: la colonización de América, la Justicia, la Iglesia, o el Estado, por ejemplo.

El Maestro Francisco de Vitoria, fallece en Salamanca, un doce de agosto de 1546, siendo enterrado en el convento de San Esteban, después de haber fundado la denominada Escuela de Salamanca. Fueron muchos sus discípulos - directa o indirectamente- como Domingo Báñez, Melchor Cano, Diego de Covarrubias, Domingo de Soto, Alonso de Veracruz, Pérez de Ayala, y — sobresaliendo entre estos- el jesuita Francisco Suárez, llamado el Doctor eximio, fundador a su vez del denominado suarismo. 


\section{RELECCIONES DE FRANCISCO DE VITORIA}

Francisco de Vitoria impartió numerosas lecciones en la Sorbona (1513-1522), en Valladolid (1523-1526), y en Salamanca (1526-1546) , excepto los cuatro últimos cursos en los que -debido a su enfermedad- fue sustituido por los maestros Gil de Nava y de Córdoba y Manrique, entre otros.

Gracias a la tenacidad de algunos investigadores recientes - como Vicente Beltrán Heredia, también dominico- nos han llegado gran parte de sus lecciones y relecciones, que no fueron escritas por F. de Vitoria, sino por algunos de sus alumnos y discípulos.

Las ideas de F. de Vitoria, como he dicho, las encontramos principalmente, en sus relecciones ${ }^{5}$ o lecciones magistrales que pronunciaba - al igual que otros profesores- ciertos días festivos, con el propósito de que pudieran acudir el mayor número de alumnos y profesores posible, siempre a modo de conferencia y como resumen o colofón a las lecciones impartidas durante el año académico.

\footnotetext{
${ }^{4}$ Cursos de Francisco de Vitoria en Salamanca:

Curso 1526-1529 Comentario a la Summa Theologiae II

Curso 1529-1531 In IV Sententiarum, materia De sacramentis

Curso 1531-1533 Comentario a Summa Theologiae I

Curso 1533-1534 Comentario a Summa Theologiae I-II

Curso 1537-1538 Comentario a Summa Theologiae III

Curso 1538-1539 In IV Sententiarum

Curso 1539-1540 Comentario a Summa Theologiae I

Curso 1540-1541 Comentario a Summa Theologiae I

Curso 1541-1542 Comentario a Summa Theologiae I-II

Curso 1542-1544 Comentario a Summa Theologiae II-II

Curso 1544-1546 Comentario a Summa Theologiae III

${ }^{5}$ Relecciones de Francisco de Vitoria en Salamanca:

De silenti obligatione, leída en Navidad de 1527

De potestate civili, leída en Navidad de 1528

De homicidio, leída en junio de 1530

De matrimonio, leída en enero de 1531

De potestate Ecclesiae prior, leída aproximadamente en enero de 1532

De potestate Ecclesiae posterior, leída en mayo de 1533

De potestate Papae et Concilii, leída en abril de 1534

De augmento charitatis, leída en abril de 1535

De eo ad quod tenetur veniens ad usum rationis, leída en junio de 1535

De simonia, leída en mayo de 1536

De temperentia, fecha de lectura desconocida

De indis, leída en enero de 1539

De iure belli, leída en junio de 1539

De magia, leída en julio de 1540

De magia posterior, leída aproximadamente en abril de1543
} 


\subsection{Relección sobre los indios recientemente hallados}

Igual que San Isidoro había defendido la representación del Papa y de los Obispos en la Iglesia, o Alfonso X había defendido la sujeción del poder eclesiástico al del Rey o Emperador, F. de Vitoria defiende la supremacía del Sabio, y ve la autoridad de los doctos en el Antiguo Testamento (Deuteronomio, capítulo 17), y también en el Nuevo Testamento en las Cartas a los Corintios de San Pablo $(12,28)$ y a los Efesios $(4,11)$, o en Mateo (23,2-3), por ejemplo.

Así en la relección que comentamos, dice: «Más. Aun supuesto que el acto sea lícito en sí mismo, desde el momento que se duda fundamentalmente de él, es obligatorio consultar y atenerse al dictamen del sabio, aunque tal vez equivocado. Por tanto, si alguien, sin el consejo de los doctores, formalizase un contrato, del que se duda entre los hombres si es lícito o no lo es, indudablemente pecaría, aun cuando, por otra parte, fuese el contrato lícito y como tal lo tuviera el contratante, no por la autoridad del sabio, sino por su propia inclinación u opinión.

Y por la misma razón, si alguien consultase a los peritos acerca de la cuestión dudosa, y resolviesen ellos que tal o cual acción u omisión era ilícita, y obrase luego el consultante contra el parecer de sus consejeros, pecaría, aun cuando de verdad fuese lícita de suyo la acción ejecutada o lícita la omisión».

Interesa observar que en opinión del traductor, F. de Vitoria indudablemente se sirvió, para sus citas bíblicas o la edición de la Vulgata de los Padres Dominicos, de París del siglo XIII, o de la Maguntina del año $1462^{6}$. Este dato es importante, porque la división de los libros de la Biblia en capítulos, no se conoció hasta el siglo XIII, y hasta el siglo XVI no se dividieron los capítulos en versículos, división que realizó por primera vez el editor francés Stéfano. Estas mejoras se indican por el traductor para una mejor localización, pero, claro está, F. de Vitoria, no cita nunca versículos.

La orden de los dominicos, como hemos dicho, se caracterizó por su dedicación al estudio y a la predicación, por eso en 1493, cuando Alejandro VI, mediante las Bulas papales, había reconocido al

${ }^{6}$ Las ediciones importantes de la Vulgata posteriores a San Jerónimo, son la de Casiodoro en el siglo VI, la de Alcuino en el siglo IX, la de Lanfranco, en el siglo XI, la del Cardenal Nicolás en el siglo XII, la de los Padres Dominicos de París, en el siglo XIII, la de Maguncia, en el siglo XV, la Políglota del cardenal Gonzalo Jiménez Cisneros, en 1517, la de Stéfano en 1528, y la de Lovaina en 1547. 
Reino de España como dueño y señor de las tierras descubiertas y por descubrir, debió de llamar poderosamente la atención un fraile que afirmaba que el hombre es imagen de Dios por su naturaleza y raciocinio, pero no por la gracia santificante necesariamente. Poniendo así en duda el dominio y la autoridad hispana sobre América.

Finaliza F. de Vitoria, con el corolario siguiente:

«De todo lo hasta aquí tratado síguese que los bárbaros, ni por sus pecados mortales, ni por el especial pecado de infidelidad, hallan obstáculo para ser verdaderos dueños, ya pública, ya privadamente, ni a titulo de ser sus dueños pecadores e infieles pueden ser ocupados por los cristianos los bienes y tierras de ellos».

\subsection{Relección del derecho de guerra de los españoles sobre los bárbaros}

Acerca de la relección del derecho de guerra de los españoles sobre los bárbaros, plantea cuatro cuestiones:

CUESTIÓN I: ¿Es lícito a los cristianos guerrear?

Comienza diciendo que podría parecer que la guerra es cosa prohibida a los cristianos, pero contra este parecer está la oposición de todos los doctores y el uso recibido en la Iglesia. Ante esto nos plantea una sola proposición: Lícito es a los cristianos el ejercicio de las armas y hacer la guerra. Pruébase dice, con San Agustín que lo afirma en multitud de lugares, por ejemplo en Contra Faustum manichaeum, en el libro De diversis Quaestionibus octoginta tribus, en el segundo libro Contra Secundinum Manichaeum, en el Sermo filii centurionis y en la carta Contra Duas Espistolas Pelagianorum libri ad Bonifacium desarrolla largamente la cuestión. Pruébase también por Santo Tomás ${ }^{7}$ y en el Antiguo ${ }^{8}$ y en el Nuevo Testamento ${ }^{9}$.

CUESTIÓN II: ¿Quién tiene autoridad para hacer o deshacer la guerra?

Después de formular tres proposiciones ${ }^{10}$, concluye que en consecuencia <evidentemente> los príncipes que no gobiernan una comu-

${ }^{7}$ Summa Teologíae II-II, q.40 al.

${ }^{8}$ Génesis 14,15; también en Salmo 5.

${ }^{9}$ San Pablo en su Carta a los Romanos $(13,4)$.

${ }^{10}$ Primera proposición: Cualquiera, incluso una persona privada, puede comprender y hacer la guerra. Es evidente - dice-, pues, según la ley antes citada, que es lícito rechazar la fuerza con la fuerza. Segunda proposición: Cualquier república tiene auto- 
nidad perfecta, sino regiones que son parte de otra república, no pueden declarar y sostener la guerra, como el duque de Alba y el conde de Benavente, cuyos señoríos son parte del reino de Castilla, más no comunidades perfectas.

CUESTIÓN III: Para ver cuál pueda ser la causa o razón justa de la guerra.

Resuelve esta cuestión con cinco proposiciones ${ }^{11}$. probadas principalmente mediante Aristóteles, San Agustín, Santo Tomás, y textos del Antiguo Testamento.

CUESTIÓN IV: Qué se nos permite en la guerra justa y de cuánta magnitud

Vitoria disecciona esta cuestión en otras cinco proposiciones ${ }^{12}$, pero además plantea también hasta doce dudas, acerca de la justicia

ridad para deshacer y llevar a cabo la guerra. La República, dice, tiene autoridad, no sólo para defenderse sino también para vengarse a sí y a los suyos, y perseguir las injurias. Lo cual se prueba, dice el dominico, con la afirmación aristotélica «la república debe bastarse a si misma» (Aristóteles III Política). Tercera proposición: En cuanto a esto el soberano tiene la misma autoridad que la nación. Y la justifica diciendo que el orden natural que exige la paz demanda que los príncipes tengan autoridad de poder declarar la guerra (San Agustín, Contra Faustum). Toda la dificultad, dice F. de Vitoria, de la cuestión está en saber qué es república y quién propiamente el llamado príncipe. Será, pues, república perfecta o perfecta comunidad aquella que es de suyo un todo completo, es decir, que no es parte de otra república, sino que tienen leyes propias, consejo propio y propios magistrados, como son los reinos de Castilla y de Aragón, el principado de Venecia y otros semejantes.

${ }^{11}$ Primera proposición: La diversidad de religión no es causa justa para hacer la guerra. La cual prueba nuevamente con santo Tomás (Summa Theologiae II q.66-a8). Segunda proposición: Tampoco es razón suficiente para hacer la guerra el ensanchamiento del Imperio. Tercera proposición: Ni la gloria del príncipe ni alguna otra ventaja para él es razón suficiente para hacer la guerra. La cual pruébase con Aristóteles (IV, Política, 10). Cuarta proposición: La única causa justa para declarar la guerra es haber recibido injuria. La cual pruébase con la autoridad de San Agustín (De diversis Quaestionibus octoginta tribus, cuestión Justa bella solent defini) y con la doctrina de Santo Tomás (Summa Theologiae I-II Q. 40.al), y de todos los doctores. Quinta proposición: No cualquier injuria y de cualquier magnitud es suficiente para declara la guerra. La cual pruébase con el Antiguo Testamento (Deuteronomio 25,2).

${ }^{12}$ Comienza con una primera proposición: En la guerra nos es lícito todo aquello que requiere la defensa del bien público. Le sigue una segunda proposición: Es lícito recuperar todas las cosas perdidas y su precio. Continúa con una tercera proposición: Es lícito resarcirse de los gastos de la guerra y de todos los daños recibidos injustamente del enemigo a expensas de sus bienes. Sigue una cuarta proposición: No solo es lícito todo lo precedente sino que <el príncipe que hace una guerra justa puede aún ir más lejos hasta > hacer cuanto sea menester para asegurar la paz y tranquilidad del lado de los enemigos a saber destruir sus fortalezas y levantar defensas en tierra de ellos. La cual se prueba porque el fin de la guerra es la paz y la seguridad. Finaliza con una quinta pro- 
en la guerra, la vida de los inocentes, los botines de la guerra o los prisioneros de guerra.

Finaliza esta relección con Tres Reglas conclusiones:

Primera regla: supuesto que el príncipe tiene autoridad para hacer la guerra, lo primero que debe procurar es no buscar ocasión de pelear, sino vivir en paz con todos los hombres, como mandó San Pablo $^{13}$.

Segunda regla: declarada con justa causa la guerra, no debe hacerse para exterminio del pueblo contra el cual se pelea, sino para lograr el fin de la guerra, la realización del derecho, la defensa de la patria, la paz y la seguridad.

Tercera regla: lograda la victoria y terminada la guerra, es menester usar el triunfo con modestia cristiana y que el vencedor se constituya en juez de entre ambas partes, una la ofendida y la otra la que perpetro la injuria, con el fin de que no como acusador, sino como juez pueda dictar sentencia con la que satisfaga a la parte perjudicada.

\subsection{Relección de la potestad civil}

Toda la cuestión de esta relección la incluye en tres conclusiones:

CONCLUSIÓN I: Toda potestad, pública o privada, por la que es administrada la república secular, no sólo es justa y legítima, sino que tiene de tal manera a Dios por autor que no podría ser quitada o subrogada por el consentimiento de todo el mundo.

F. de Vitoria analiza las diferentes causas - porque como dice Aristóteles: «tenemos por sabida una cosa cuando conocemos todas sus causas»- y las agrupa en tres apartados:

1. Causa final y necesidad menor del poder civil ${ }^{14}$. No basta dice, la propia familia para rechazar toda violencia e injuria, por ello Cam y Nemrod se vieron forzados a ser los primeros en agruparse en una ciudad $^{15}$. Añade que es, pues, muy claro que la fuente y origen de las

\footnotetext{
posición: No sólo es lícito lo dicho, sino también lograda la victoria y recuperadas las propiedades y aun habidas paz y seguridad, es lícito vengar la injuria recibida y batir a los enemigos y castigarlos según la magnitud de sus delitos.

${ }^{13}$ San Pablo en su Carta a los romanos, capítulo 12.

${ }^{14}$ La enumeración es mía, ya que F. de Vitoria no enumera las causas que trata.

${ }^{15}$ Génesis, capítulo 10.
} 
ciudades no es un invento de los hombres ni artificio, sino cosa nacida de la naturaleza, tal cual, para tutela y conservación de los mortales.

2. Causa material del poder civil. Más, la causa material en que esta potestad reside por derecho natural y divino es la misma a la cual de suyo le compete gobernarse y administrarse y dirigir todas sus potestades al bien común. Lo cual prueba con cinco argumen$\operatorname{tos}^{16}$, y nos recuerda que San Isidoro, escribió: «La común posesión de la única libertad del derecho natural es usar de la propia libertad». Por todo lo cual, se concluye que no nos es lícito a los cristianos tener príncipes.

Por tanto nosotros, con todos los sabios, decimos mejor: La monarquía o potestad regia no sólo es justa y legítima, sino que los reyes tienen su poder del derecho divino y natural, y no de la república $<$ ni, en suma, $>$ de los hombres. Pruébase también por las autoridades ${ }^{17}$. Añade, que $<$ es evidente $>$ pues, que la potestad real $<$ procede, no de la república, sino del mismo Dios, como opinan los doctores católicos.

El poder reside en la república, más, como naturalmente no puede ejercerlo, naturalmente debe traspasarlo. Pero el traspaso no es una delegación de tal suerte que haya en la sociedad dos poderes, el real y el popular, sino una transmisión total, una especie de donación, de tal manera que el poder cambia de sujeto y no hay dos sujetos de él. Y añade: el pueblo no es libre de transmitirla o de dejar de transmitirla, y de tal suerte debe transmitirla, que no quede en él nada de ella, como corresponde a su nativa imposibilidad de ejercerla.

3. Causa formal del poder civil. Pública potestad dice es la facultad, autoridad o derecho de gobernar la república civil. Por tanto, si

\footnotetext{
${ }^{16}$ Argumento primero: El hombre está dotado de libertad, pues en aquel estado feliz de inocencia cada hombre hubiese sido señor y a nadie hubiese servido; Segundo: A todos los hombres se dijo desde el principio: «Dominad a los peces del mar y a las aves del cielo». Tercero: En la ley natural no leemos que hubiese habido algún príncipe entre los adoradores del verdadero Dios. Cuarto: Porque el principado tuvo origen de la tiranía: «Primeramente Nemrod, que 'perteneció a' la posteridad reprobada por Noé, asumió la tiranía, al ser hijo de Cam» (Génesis 10,8); Quinto argumento: No callaron respecto a esto los Santos Padres. San Gregorio dice que es muy contra naturaleza querer dominar un hombre a otro, como que por derecho natural todos los hombres son iguales.

${ }^{17}$ Aristóteles, Ética, libro V; también en el Antiguo Testamento con José exactor de impuesto, Jacob varón justo y con la sabiduría de Job, y en Deuteronomio Capítulo X; y en el Nuevo Testamento en Romanos,13, Epístola a Tito3 Primera Epístola a Timoteo 2,2 y I Pedro 2.
} 
todos los ciudadanos conviniesen en prescindir de las autoridades para no estar obligados $<$ y no ejercer el mando sobre nadie para no estar obligados por ley alguna> el pacto sería tanto nulo e inválido como antinatural. De estas cosas se sigue un nuevo corolario no despreciable, principalmente para aquellos que viven bajo un régimen monárquico. Las ciudades que no tienen rey y se gobiernan por organización popular, suelen pregonar muy alto su libertad.

Finaliza esta conclusión I, con tres corolarios: Primero: No hay mayor libertad <bajo el principado real> que bajo los regímenes aristocráticos y democráticos. Segundo: Toda república puede ser lícitamente castigada por el pecado del rey. Tercero: Ninguna guerra es justa si se hace con mayor mal que bien y utilidad de la república, aunque por otra parte sobren los títulos que hagan justa la guerra.

CONCLUSIÓN II: Así como la mayor parte de la república puede constituir rey sobre toda la república, aún resistiéndose el resto, puede legítimamente crear un monarca al que están obligados a obedecer todos los príncipes y todas las provincias.

En relación con la primera parte de esta conclusión, dice que es cierto, porque si se exigiera el consentimiento de todos, no es posible obtenerlo nunca de la muchedumbre. Además añade, el rey lo es sobre toda la república. No sólo sobre cada uno de los ciudadanos, sino sobre toda la república, y por último, que la mayor parte de los cristianos podría constituir un monarca. Pues toda la iglesia es como una sola república y un solo cuerpo.

De esta conclusión síguese un corolario: Que en las ciudades libres, como son Venecia y Florencia, podría la mayor parte elegirse rey, aun oponiéndose los demás.

CONCLUSIÓN III: Las leyes constituciones de los príncipes de tal manera obligan que los transgresores son reos de culpa en el fuero de la conciencia, <y los preceptos de los padres sobre los hijos y los de los maridos sobre las mujeres tienen también esta naturaleza y poder $>$.

A mi me parece, dice F. de Vitoria, que no puede dudarse que las leyes civiles obligan en el fuero de la conciencia ${ }^{18}$. Y continúa, más pueden dudarse ciertos aspectos (y establece hasta seis dudas) ${ }^{19}$ :

${ }^{18}$ San Pablo en Carta a los Romanos, 13.

${ }^{19}$ Primera duda: A qué culpa obligan las leyes civiles, si a mortal o solo a venial. Que obliguen alguna vez a mortal, nos lo dice San Pablo, cuando dice que los que no obedecen se ganan la condenación; Segunda: ¿Cómo podrá conocerse que las leyes humanas obliguen a mortal o venia, cuando ellas mismas no lo significan ni el legislador pien- 


\subsection{Relección de la potestad de la Iglesia}

CUESTIÓN I: Comienza diciendo que Iglesia es un vocablo griego que significa concilio, reunión, congregación. Así «Iglesia» es un vocablo sinónimo de «Sinagoga», pues «Sinagoga» significa también «Congregación».

No obstante, entre ambos nombres «Iglesia» y "Sinagoga» hay su diferencia, continúa F. de Vitoria, Iglesia y Sinagoga son dos nombres griegos que significan lo mismo, es decir, reunión. Más si penetramos un poco, veremos que Iglesia significa Convocación y Sinagoga significa Congregación. Y entre convocar y congregar hay la misma diferencia que entre llevar guiando y llevar arrastrando.

Más los apóstoles nunca llamaron a nuestra Iglesia Sinagoga, sino siempre Iglesia, ya para distinguir la una de la otra, ya porque entre CONGREGACIÓN o SINAGOGA, y CONVOCACIÓN o IGLESIA, hay alguna distancia, a saber: que congregarse lo hacen también los ganados y ellos propiamente, pues a su reunión se llama GREY, rebaño. El ser convocado es más propio de criaturas racionales. Y añade: lo mismo advierte San Isidoro para hacer ver la irracionalidad de los judíos.

CUESTIÓN II: ¿Hay en la Iglesia alguna otra dignidad o autoridad eclesiástica distinta de la civil?

Como expone Santo Tomás, parece que la potestad comprende no sólo cierta potencia para obrar, sino también cierta preeminencia y autoridad. Y concluye: «Es menester en la Iglesia, aparte de la potestad civil y laica otra espiritual». Y se prueba: En la Iglesia hay muchas y varias acciones que no pertenecen a una sola potestad: unas pertenecen a la potestad civil, otras a la espiritual. Más las potestades se

\footnotetext{
sa eso cuando da la ley? Contesto que ni la ley divina y mucho menos en la natural se significa siempre qué precepto es de cosa mortal y cuál de venial. Tercera: ¿Podría el rey no obligar a culpa ni siquiera? Se responde que no hay duda que puede, como puede el legislador eclesiástico. Cuarta: ¿Obligan las leyes a los legisladores, mayormente a los reyes? A algunos les parece que no, mas esta obligación es indirecta. Confirmase esto con lo que sucede en los pactos: libremente se pacta, pero los pactos obligan. Y termina con un corolario: El derecho de gentes no sólo tiene fuerza de pacto y acuerdo entre los hombres, sino que tiene fuerza de ley; pues tiene todo el mundo, que es como una república universal, poder de dar leyes equitativas y convenientes a todos, cuales son las del derecho de gentes. Quinta: ¿Cesando la razón de la ley, cesa la obligación? Es necesaria la causa o finalidad de la ley, tanto para presentar a ésta como para conservarla. Sexta duda: ¿Obligan las leyes de los tiranos? Parece que estas leyes no tienen fuerza alguna. Pero es lo contrario.
} 
distinguen por el fin, como las potencias por el objeto. Luego, aparte de la potestad civil es menester poner otra espiritual ${ }^{20}$.

CUESTIÓN III: Si produce la potestad eclesiástica algún efecto propio y verdaderamente espiritual. Distingue aquí, F. de Vitoria, entre potestad de orden y de jurisdicción y concluye: Ambas potestades, la de orden y la de jurisdicción, producen efecto verdaderamente espiritual.

La cuestión ésta — dice— es la misma que aquella otra: si alguna vez mediante el sacramento de la penitencia se confiere la primera gracia. Lo que confirma con cinco razones de los cuatro evangelistas.

CUESTIÓN IV: ¿Por qué derecho ha sido introducida la potestad eclesiástica?

Mediante diferentes proposiciones ${ }^{21}$ concluye que los apóstoles recibieron todo su poder de Jesucristo, verdadero Dios y Señor, por tanto, toda la potestad de la Iglesia es verdadero derecho divino y positivo.

CUESTIÓN V: Cuándo tuvo su origen la potestad eclesiástica. En la séptima proposición dice que: La autoridad perfecta y propiamente espiritual principio de toda ella desde el advenimiento de Jesucristo, que fue el primer autor y dador de las llaves y de la potestad espiritual y que podía por propia autoridad y gracia perdonar los pecados por ser su potestad de excelencia.

Pruébase que tal autoridad tuvo Cristo — dice F. de Vitoria-, por Mateo capítulo 28, Marcos capítulo 2 y Lucas capítulo 7; y que la dejó en su Iglesia, es manifiesto por Mateo capítulos 16 y 18; Juan capítulo 5; Primera Carta a los Corintios 2, etc.

${ }^{20}$ F. de Vitoria diferencia entre Potestad en la república (Romanos 13,3); Potestad distinta de la civil (Juan 20); Potestad y autoridad en la Iglesia, y Potestad temporal y civil (Romanos 13)

${ }^{21}$ Primera proposición: Toda esta potestad no tiene ni pudo tener en toda su amplitud origen del derecho positivo.

Confirmase dice, que no pudo esta potestad tener origen civil (Cfr. Marcos 2). Confirmase también porque Jesucristo, que es verdadero Dios, fue el primero que dio las llaves del Reino de los Cielos. Segunda proposición: Tampoco pudo esta potestad tener su origen del derecho natural». Se confirma dice, porque el conocimiento natural no se extiende a los efectos de esta potestad; luego tampoco ni el derecho natural ni la potestad natural (Epistola a los Romanos 4 y ss.). Para sintetizar terminaremos esta cuestión con la cuarta proposición (sexta del texto latino): Toda la potestad eclesiástica y espiritual que hay hoy en la Iglesia es de derecho divino positivo, mediata o inmediatamente. 

vil.

CUESTIÓN VI: Si la potestad espiritual es superior a la potestad ci-

La cuestión es ésta, mas, como el Papa es el Príncipe Sumo de toda la potestad eclesiástica, pregúntese si el Papa es superior sobre todos los príncipes y potestades temporales. Más se pregunta: Si el Papa es superior a la potestad civil en jurisdicción y autoridad.

Sylvestre y muchos otros piensan que el Papa es señor de todo el mundo con dominio propio y autoridad en todo el mundo sobre todos los príncipes. Esto, dice F. de Vitoria, es falso - y añade- yo creo que es una patraña para adular y lisonjear a los pontífices; cosa que no hicieron Juan Andrés o Santo Tomás, que celosísimo de la autoridad de los Pontífices, jamás atribuyó tal poder al Soberano Pontífice. Mas adelante continúa y dice: en Cristo, como confiesan los doctores, hubo potestad de excelencia, la cual, sin embargo, no dejó en la Iglesia.

CUESTIÓN VII: Si los clérigos están exentos de la potestad civil.

Los clérigos dice, en una primera proposición, están por derecho exentos y libres de la potestad civil, de suerte que no pueden legalmente ser juzgados ni criminal ni civilmente por el juez lego. Y añade, en multitud de lugares del derecho consta eso y no os lo he de recordar aquí; lo contrario está condenado por el Concilio de Constanza.

CUESTIÓN VIII: ¿En quién reside la potestad eclesiástica?

Concluye afirmando que es una patraña sofística imaginar la potestad eclesiástica en la comunidad, de la que nunca había de usar, sino que todas las cosas son y siempre han sido hechas por los prelados, que sucedieron a los apóstoles; al igual que, si hubiesen sido constituidos por la naturaleza misma príncipes en la república civil y magistrados suficientes para gobernarla, en vano soñaríamos una potestad inmediatamente residente en la república.

CUESTIÓN IX: Si la potestad eclesiástica está en todos los cristianos.

Contra todos los herejes, dice F. de Vitoria, pongo una conclusión: $\mathrm{Ni}$ todos los cristianos son sacerdotes, ni todos son iguales ${ }^{22}$. Y más adelante plantea una duda; Si hay cristianos que no pueden ser capaces de potestad eclesiástica.

${ }^{22}$ San Pablo en Carta a los Romanos, 12 
Concluye diciendo que, en primer lugar, se duda de las mujeres; más parece que si, porque San Pablo a los Gálatas les dijo que ante Cristo no hay judío y griego, siervo y libre, varón y hembra. Por este motivo, no parece que las mujeres deban ser rechazadas en la ley eclesiástica para servir a Dios. No obstante, la conclusión que agrada a todos los autores es que las mujeres no puedan ser sacerdotes ni recibir orden ni potestad eclesiástica, por tanto, aunque defendí que lo contrario podía tal vez no ser absurdo, no obstante, para no traer conclusiones nuevas al uso de los jurisconsultos, pruebo esta conclusión por la doctrina de los doctores.

Y dice más: Las abadesas y otras superioras de monjas no tienen potestad alguna espiritual ni jurisdicción. Acerca de lo cual afirma que no querer en absoluto obedecer a la abadesa es mortal; pero la abadesa, añade, no puede dar más preceptos que los contenidos en la regla.

Finaliza afirmando que ningún otro cristiano, aparte de las mujeres, es excluido por derecho divino de la potestad eclesiástica. Y digo con los doctores, que aun el niño y el loco, pueden ser sacerdotes, porque su impedimento es contingente; no así en las mujeres.

Le sigue otra proposición: La elección del Sumo Pontífice corresponde en tal caso al clero, no al pueblo. Acerca de lo cual dice, es absurdo que la providencia del Sacerdocio fuera confiada a aquellos - la plebe- que solo por casualidad podrían proveer rectamente.

Tal elección sería totalmente imposible, como es imposible que todo el pueblo se reúna para la elección, ni, aun después que se hubiesen reunido, podría conseguirse que la mayor parte optara por una misma persona.

\section{EL OLVIDO DEL MAESTRO VITORIA}

A continuación enunciaré algunas de las causas que, a mi juicio, podrían ser el motivo del olvido de la figura — que no de la doctrinade F. de Vitoria:

\section{a) Francisco de Vitoria no llevó sus escritos a la Imprenta}

Sabemos que en 1538 el maestro Francisco de Vitoria intentó llevar a la imprenta sus lecciones, pero la enfermedad — que le acompañaría hasta su muerte en 1546 - se lo impidió, de forma que como 
dice Díaz ${ }^{23}$, sus lecciones y relecciones no fueron dadas a la imprenta durante su vida, pero sí fueron conservadas por sus alumnos, para quien F. de Vitoria era sobre todo "el maestro».

Está acreditado que en 1548, en el seno de la Universidad de Salamanca, se debatió sobre la conveniencia o no de imprimir los tratados realizados por el maestro Francisco de Vitoria, pero casi todos se perdieron. Recientemente el también dominico, Vicente Beltrán Heredia ha conseguido reunir parte de los manuscritos del maestro (localizados en la Biblioteca Apostólica Vaticana de Roma, en la Biblioteca Universitaria de Salamanca, en la Biblioteca Universitaria de Valencia, etcétera) la mayoría copiados por sus alumnos y discípulos, algunos destacados como Martín Ledesma, el cual como catedrático de Coimbra, publicaría parte de las lecciones y relecciones de F. de Vitoria en «Secundae quartae» en el año 1560 en Coimbra.

\section{b) El Emperador Carlos V requisó los manuscritos de Vitoria}

Como señala Díaz ${ }^{24}$, Carlos V invitó a F. de Vitoria a asistir al Concilio de Trento en calidad de teólogo imperial, pero su estado de salud - llevaba años enfermo de gota- se lo impidió, de hecho en los últimos años de su vida ya no podía caminar y sus alumnos le llevaban en andas para dictar sus clases.

Pero la relación entre ambos no siempre fue así, ya que años antes F. de Vitoria no dudó en oponerse a Carlos V - el Emperador más poderoso de todo el mundo conocido- a propósito de su política con Francia. Igualmente, con motivo de las opiniones de F. de Vitoria acerca de la justicia en la conquista de América, Carlos V escribe una dura carta al prior de San Esteban, en los siguientes términos:

«He sido informado que algunos maestros religiosos de esa casa han puesto en plática y tratado en sus sermones y en repeticiones, del derecho que nos tenemos a las Indias, Islas y tierra firme del mar Océano ... por tanto, encargo y mando que luego, sin dilación alguna, llaméis ante vos a los dichos maestros religiosos ... y recibáis dellos juramento para que declaren en qué tiempos y lugares y ante qué personas han tratado y afirmado lo susodicho, sí en limpio como en minutas y memoriales».

\footnotetext{
${ }^{23}$ Vid. DÍAZ, Bárbara El internacionalismo ... p. 25.

${ }^{24}$ Ibidem p. 30.
} 
Finalmente, el Emperador ordena recoger todos los manuscritos ${ }^{25}$ que se refieran a dichos asuntos y enviarlos a la Corte.

\section{c) Francisco Suárez sistematizó la doctrina de Vitoria}

Cano, Covarrubias, Soto y otros maestros salmantinos continuaron la línea de pensamiento iniciada por Francisco de Vitoria, y sistematizada - un siglo más tarde- por el eximio Francisco Suárez, culminando así, como sostiene Brown ${ }^{26}$, la escuela española del Derecho Internacional creadora de esa Ciencia.

En este punto se suscita otra cuestión acerca de ¿Por qué inicialmente no se consideró a Francisco de Vitoria, como padre del Derecho Internacional moderno, y sí al holandés Hugo Grocio, aun cuando era un siglo posterior en el tiempo?

Grocio cita más de cincuenta veces a Vitoria ${ }^{27}$, en su famoso tratado De iure belli ac pacis, donde expone las ideas fundamentales de la doctrina que ha había sido defendida por el dominico. Además, como dice Brown ${ }^{28}$, ni en cuanto al método, ni en cuanto al fondo principal difiere esencialmente la doctrina del holandés con la del dominico, porque si Grocio construyó «el edificio», lo hizo con «los materiales» proporcionados principalmente por Vitoria.

Así, la razón del olvido, pues, podría ubicarse en el jesuita Francisco Suárez ${ }^{29}$, que sistematizó doctrina vitoriana y, como señala Ocaña ${ }^{30}$, se constituye en el eslabón insustituible entre la escuela de Salamanca - fundada por el dominico Francisco de Vitoria- y el holandés Hugo Grocio, encontrándose la principal diferencia, como sostiene Brown ${ }^{31}$, entre los religiosos españoles, en el Derecho de

\footnotetext{
${ }^{25}$ Vid. PEREÑA, L., La Escuela de Salamanca. Proceso a la conquista de América, Salamanca 1986, p. 258.

${ }^{26}$ Cfr.BROWN SCOTT, J., El origen español del Derecho Internacional Moderno, Valladolid 1928, p. 188 y ss.

${ }^{27}$ Cfr.OCAÑA, Vida, muerte y resurrección, Anales del Seminario de Historia de la Filosofía, n. ${ }^{\circ}$ 1,1996, p. 306.

${ }^{28}$ Vid. BROWN SCOTT, J., El origen .... cit.307,nt 40.

${ }^{29}$ Francisco Suárez nacido en Granada, en 1548, dos años después de fallecer Francisco de Vitoria. De familia bien, con dieciséis años ingresa en la Compañía de Jesús en Salamanca. Más tarde, estudió filosofía y teológica, materias que enseño en las Universidades de Roma, Alcalá de Herrares, Salamanca y Coimbra, donde en 1597 se editaron sus Disputationes metaphysicae. Falleció en Lisboa en 1617.

${ }^{30}$ Vid. OCAÑA, Vida,...cit. p. 304.

${ }^{31}$ Cfr. BROWN SCOTT, J., El origen .... cit.188.
} 
guerra, que Vitoria hace referencia a la ley española, mientras que Suárez no hace referencia a casos especiales.

\section{A MODO DE CONCLUSIÓN}

F. de Vitoria sostuvo, desde su cátedra, que ni el Papa ni el Emperador, podían ser considerados «señores del universo», que, al contrario, era obligatorio consultar y atenerse al dictamen del Sabio, aunque estuviera equivocado. Estableció una doctrina acerca de los derechos humanos, que aún después de cinco siglos, continúa vigente.

Así, en pleno siglo XVI, cuando el escenario internacional se caracterizaba por la hegemonía militar española, consiguió que, por iniciativa de una junta convocada por el Emperador Carlos V, se promulgaran las Nuevas Leyes en 1542, las cuales lograron, gracias a la doctrina vitoriana, un trato más humano y sin armas.

La doctrina vitoriana está contenida, como hemos podido comprobar, principalmente en sus relecciones, así:

En Relectio De Potestate civili, leída en 1528, estableció que las leyes civiles obligan en el fuero de la conciencia.

Igualmente, en Relectio De Potestate Ecclesiae, leída en 1532, sostuvo que la potestad eclesiástica es un verdadero derecho divino y positivo.

Por otro lado, en Relectio De indis, leída en 1539, es el primero en defender y argumentar que los indios tienen los mismos derechos que cualquier otro ser humano y que eran dueños de todos sus bienes y tierras, y que no podían ser desposeídos por los cristianos.

Por último, en Relectio De iure belli, leída en 1539, establece los límites del uso de la fuerza para resolver los conflictos entre los distintos pueblos y sostiene que el príncipe tiene autoridad para hacer la guerra, pero lo primero que debe procurar es no buscar ocasión de pelear.

En suma, Francisco de Vitoria modificó los cimientos del Derecho moderno, de forma que en la Independencia de los EE.UU. de 1776 y en la Revolución Francesa de 1789, podemos apreciar los primeros indicios de la sociedad internacional vitoriana, que serían plasmados en los derechos de los negros o de las mujeres, por ejemplo. Así 
como afirma Ocaña ${ }^{32}$ : «La doctrina de Vitoria con respecto a que los derechos humanos están muy por encima del poder y la jurisdicción del Papa o del Emperador, se infiltró y fue calcada tanto en la realidad histórica o las relaciones sociales de nuestro tiempo, como en la propia Constitución de las diferentes democracias actuales».

En este sentido, hoy en día, en pleno siglo XXI, caracterizado por una incipiente hegemonía militar estadounidense, la O.N.U. debería frenar las pretensiones unilaterales de algunos países, reformando el sistema internacional desde una óptica vitoriana, para solucionar importantes problemas que afectan a todo el orbe, como los económicos o demográficos.

Es más, la doctrina del maestro Vitoria, tiene todavía mucho que decir, porque como dice Federico Fernández de Buján ${ }^{33}$ : «Una visión más vanguardista pretende, desde hace algunos años, situar más el acento en el futuro y considerar que el actual Derecho Internacional público, debe entenderse como el precedente histórico de un deseable Derecho común de la Humanidad».

${ }^{32}$ OCAÑA, Vida, ... cit. p. 297.

${ }^{33}$ Vid. FERNÁNDEZ DE BUJÁN, Federico, Nociones Jurídicas Básicas, vol. I, Madrid 2008, p. 117. 